\title{
Ranibizumab in monotherapy and combined with photodynamic therapy for retinal angiomatous proliferation
}

This article was published in the following Dove Press journal:

Clinical Ophthalmology

17 May 2016

Number of times this article has been viewed

\author{
Luis Arias ${ }^{1-3}$ \\ Francisco Gómez-Ulla ${ }^{2-4}$ \\ José M Ruiz-Moreno $2,3,5$ \\ 'Ophthalmology Department, Bellvitge \\ University Hospital, C/Feixa Llarga, \\ L'Hospitalet de Llobregat, Barcelona, \\ ${ }^{2}$ Spanish Vitreoretinal Society (SERV), \\ C/Xosé Chao Rego, Santiago de \\ Compostela, ${ }^{3}$ RETICS OFTARED, \\ Institute of Health Carlos III, C/ \\ Sinesio Delgado, Madrid, ${ }^{4}$ Gómez-Ulla \\ Eye Institute, Santiago de Compostela, \\ ${ }^{5}$ Department of Ophthalmology, \\ Albacete University Hospital, Avenida \\ de Almansa s/n, Albacete, Spain
}

Correspondence: Luis Arias Ophthalmology Department, Bellvitge University Hospital, C/Feixa Llarga s/n 08907, L'Hospitalet de Llobregat, Barcelona, Spain Tel +3493620898469 Email luisariasbarquet@gmail.com
Purpose: To compare the effects of intravitreal ranibizumab in monotherapy (group A) and combined with photodynamic therapy (PDT) with verteporfin (group B) in retinal angiomatous proliferation (RAP) treatment.

Methods: This was a multicentric, prospective, randomized clinical study conducted with parallel groups. The study eye in both groups received ranibizumab on days 1, 30, and 60 (loading dose); group B received PDT additionally on day 1. Early Treatment Diabetic Retinopathy Study (ETDRS) visual acuity (VA) testing and optical coherence tomography were performed monthly, and fluorescein angiography and indocyanine green angiography were performed quarterly. Retreatment criteria were leakage in fluorescein angiography or indocyanine green angiography, mean foveal thickness increase $\geq 100 \mu \mathrm{m}$, or VA decrease $\geq 5$ letters.

Results: Twenty patients were recruited (ten patients in each group). Six eyes had previous treatment (three eyes in group A and three eyes in group B), so only 14 eyes were naïve. At 12-month follow-up, mean VA improved +1.5 letters in group A and +5.6 letters in group B (analysis of variance test; $P>0.05$ ). Two patients (20\%) in both groups gained $\geq 15$ letters (chi-square test; $P>0.05$ ). Mean changes in greatest linear dimension and in foveal thickness were not statistically significant between groups of treatment (analysis of variance test; $P>0.05$ ). Mean retreatments per patient were 1.8 (group A) and 0.9 (group B) (Mann-Whitney $U$-test; $P>0.05$ ). One patient died due to underlying disease not related to study medication.

Conclusion: Intravitreal ranibizumab administered in monotherapy or combined with PDT was efficacious in terms of VA stabilization in patients with RAP.

Keywords: age-related macular degeneration, intravitreal injection, photodynamic therapy, ranibizumab, retinal angiomatous proliferation, verteporfin

\section{Introduction}

Retinal angiomatous proliferation (RAP) has recently been described as a variant of exudative-type age-related macular degeneration (ARMD), characterized by the initial presence of new intraretinal capillaries that grow toward the subretinal space and choroid. ${ }^{1-3}$

Three stages of the disease are distinguished: stage I, characterized by the presence of intraretinal neovascularization; stage II, in which new capillaries are formed in the subretinal space (subretinal neovascularization); and stage III, characterized by choroid neovascularization $(\mathrm{CNV})$ with retinochoroidal anastomosis. ${ }^{1}$

Approximately $10 \%-15 \%$ of all eyes with exudative ARMD present RAP. ${ }^{1,4,5}$ The diagnosis of RAP is complex, since in most cases, fluorescein angiography (FA) is used, revealing a blurred area of exudate within the intra- or subretinal space 
that is usually classified as occult CNV. In this context, angiography with indocyanine green (ICG) is recommended for clear identification. Given the difficulty of its detection, it is estimated that RAP could represent almost a quarter of all cases of occult or minimally classical CNV., ${ }^{1,6}$ The natural course of RAP differs from that in typical exudative ARMD, and its prognosis in relation to treatment response is poorer. ${ }^{7,8}$

Different therapeutic approaches have been evaluated in RAP treatment,,${ }^{9,10}$ such as surgery, ${ }^{11,12}$ laser photocoagulation, ${ }^{8}$ transpupillary thermotherapy, ${ }^{13}$ photodynamic therapy (PDT) with verteporfin, ${ }^{14-16}$ and the intravitreous injection of triamcinolone, ${ }^{12,17}$ among others. More recently, several studies have been published which analyze the efficacy of antiangiogenic drugs in monotherapy ${ }^{18-21}$ or in combination with other treatments, ${ }^{22-24}$ revealing visual improvement in certain cases.

Nowadays, there is no evidence to support higher efficacy with one treatment strategy over the rest, since no randomized, controlled clinical trials assessing long-term efficacy have been conducted. ${ }^{9}$ Ranibizumab, which is administered as an intravitreal injection, is an antiangiogenic drug that has shown efficacy and safety for the treatment of wet ARMD. ${ }^{9,18,22-24}$ Ranibizumab is a humanized monoclonal antibody fragment designed to inhibit VEGF-A, a key protein in angiogenesis, preventing the growth of new blood capillaries and leakage. ${ }^{25,26}$

Ranibizumab has been used for the treatment of retinal angiomatous proliferation (RAP) lesions as well, exhibiting a similar profile in comparison with regular ARMD lesions. ${ }^{18,19,24}$

In the case of PDT, following luminous activation after the intravenous injection of a photosensitive drug, endothelial damage is induced that favors localized platelet adhesion, resulting in occlusion of the anomalous vessels with selective sealing of the neovascularization - without affecting the proximal neurosensory retinal layer. PDT with verteporfin has been shown to be effective in the treatment of CNV associated with exudative ARMD. ${ }^{16}$

The existing data suggest that combined administration of PDT with verteporfin and an antiangiogenic or antiinflammatory drug could offer advantages over monotherapy, slowing or completely arresting the neovascularization process found in RAP. ${ }^{22,24}$

The purpose of the present study was to obtain efficacy and safety data on ranibizumab in monotherapy and in combination with PDT with verteporfin for the treatment of RAP during 1 year of follow-up.

\section{Methods \\ Study design}

A randomized, open-label, multicenter, parallel-group study was designed, considering the inclusion of a total of 30 patients with RAP (15 in each treatment group). The following groups were established: group A (ranibizumab [Lucentis ${ }^{\circledR}$; Novartis, Basel, Switzerland] $0.5 \mathrm{mg}$ in monotherapy, administered as an intravitreal injection) and group B (combination of ranibizumab $0.5 \mathrm{mg}$ and PDT with verteporfin [Visudyne ${ }^{\circledR}$; Novartis, Basel, Switzerland]). The patients were randomized in 1:1 proportion to treatment on a stratified basis according to the stage of RAP. In group B, PDT treatment was guided both by FA and indocyanine green angiography (ICGA).

The study included patients aged $\geq 50$ years, diagnosed with RAP in stages I-III, with best-corrected visual acuity (BCVA) in the study eye between 73 and 24 letters, measured by Early Treatment Diabetic Retinopathy Study (ETDRS) charts at a distance of $4 \mathrm{~m}$ or Snellen equivalent. Written informed consent was obtained from all cases before inclusion in the study. Patients receiving topical or systemic steroids or PDT with verteporfin in the study eye during the three previous months or antiangiogenic treatment during the six previous months were excluded from the study. Subjects with cataracts in the study eye that were likely to require surgery during the study period, patients with a history of glaucoma in the study eye or with an intraocular pressure $\geq 23 \mathrm{mmHg}$ or with uncontrolled arterial hypertension (systolic blood pressure $>180 \mathrm{mmHg}$ and/or diastolic blood pressure $>100 \mathrm{mmHg}$ ), women of childbearing potential not using effective contraceptive methods, as well as pregnant and nursing women or women with suspected pregnancy were also excluded.

The study was approved by the ethics committees of all participating centers and authorized by the Spanish Agency for Medicines and Medical Devices. The study was conducted in accordance with the principles of the Declaration of Helsinki.

\section{Treatment scheme}

Table 1 shows the treatment scheme followed in both groups. Group A received ranibizumab $0.5 \mathrm{mg}$ on days 1 , 30 , and 60 of the trial (loading phase). In addition, group B also received PDT with verteporfin on day 1 . When needed, patients in both groups received retreatment in case of leakage detected on FA or ICGA, loss of over five letters in visual acuity (VA), or a mean increase in macular thickness of $\geq 100 \mu \mathrm{m}$ as measured by optical coherence tomography 
(OCT). All retreatments in group B consisted of combined therapy of a single intravitreal injection of ranibizumab and PDT with verteporfin. In addition, in group B, ranibizumab $0.5 \mathrm{mg}$ could be administered in monotherapy as rescue therapy, if necessary.

\section{Efficacy and safety evaluation}

The efficacy of treatment was determined through monthly ETDRS chart evaluation of VA and OCT. FA and ICG were performed every 3 months.

Safety was assessed by clinical examination and complementary ophthalmological tests. All reported adverse events (AEs) occurring during the clinical trial, as well as concomitant medication were recorded.

\section{Statistical analysis}

Given the exploratory nature of the study, the efficacy analysis was carried out with an intent-to-treat sample including the randomized patients who had received at least one treatment, with baseline and one posttreatment assessment of the principal study variable, BCVA - the last observation carried forward method was applied to estimate the missing values. The safety sample, in turn, comprised all patients included in the trial who had received at least one dose of the study drug.

The categorical variables were described as absolute and relative frequencies, while the continuous variables were reported as mean, median, standard deviation, and range. Comparison of the quantitative variables was based on the use of parametric (Student's $t$-test or analysis of variance [ANOVA]) or nonparametric tests (Mann-Whitney $U$-test), depending on the characteristics of the study variables. The chi-square test was used to compare the categorical variables. All statistical calculations were performed using the Statistical Analysis Software Version 9.1.3 (SAS Institute Inc., Cary, NC, USA), applying two-tailed tests, with a level of significance of 0.05 .

\section{Results Description of the patient baseline characteristics}

A total of 20 patients (20 eyes under study) were included in the trial, and all were evaluable for efficacy (intent-to-treat sample) and safety analysis. Patients were randomized to therapy, with ten eyes evaluated in each group.

Table 2 shows the demographic and clinical characteristics related to the study disease at baseline, according to treatment groups. Seven patients $(70 \%)$ in group A were females and six patients $(60 \%)$ in group B were males. The 
Table 2 Demographic and clinical baseline characteristics of each group

\begin{tabular}{|c|c|c|c|}
\hline & Group A $(n=10)$ & Group B $(n=10)$ & $P$-value \\
\hline \multicolumn{4}{|l|}{ Sex, n (\%)* } \\
\hline Male & $3(30.0)$ & $6(60.0)$ & \multirow[t]{2}{*}{0.3698} \\
\hline Female & $7(70.0)$ & $4(40.0)$ & \\
\hline Age, years $(\text { mean } \pm \mathbf{S D})^{*}$ & $79.5 \pm 8.0$ & $79.2 \pm 3.7$ & 0.9702 \\
\hline \multicolumn{4}{|l|}{ RAP stage, n (\%)* } \\
\hline I & $2(20.0)$ & $3(30.0)$ & \multirow[t]{3}{*}{1.0000} \\
\hline II & $6(60.0)$ & $5(50.0)$ & \\
\hline III & $2(20.0)$ & $2(20.0)$ & \\
\hline \multicolumn{4}{|l|}{ Angiographic lesion dimensions ${ }^{\dagger}$} \\
\hline Greatest linear dimension, $\mu \mathrm{m}($ mean $\pm \mathrm{SD})$ & $3,827.6 \pm I, 370.2$ & $3,297.7 \pm 1,740.7$ & 0.4965 \\
\hline Total area of lesion, $\mathrm{mm}^{2}($ mean $\pm \mathrm{SD})$ & $8.4 \pm 6.1$ & $9.3 \pm 7.7$ & 1.0000 \\
\hline Total area of CNV, mm² (mean \pm SD) & $1.9 \pm 1.6$ & $2.3 \pm 1.9$ & 1.0000 \\
\hline \multicolumn{4}{|l|}{ Optical coherence tomography } \\
\hline Foveal thickness, $\mu \mathrm{m}$ (mean $\pm \mathrm{SD})$ & $438.7 \pm 86.6$ & $361.5 \pm 81.2$ & 0.0891 \\
\hline \multicolumn{4}{|c|}{ Fluorescein angiographic pattern of CNV, $n(\%)^{*}$} \\
\hline Predominantly classic & $\mathrm{I}(\mathrm{I} 0.0)$ & $\mathrm{I}(\mathrm{I} 0.0)$ & 1.0000 \\
\hline Minimally classic & $5(50.0)$ & $4(40.0)$ & 0.6499 \\
\hline Occult & $4(40.0)$ & $5(50.0)$ & 0.6499 \\
\hline \multicolumn{4}{|l|}{ CNV location, n (\%)* } \\
\hline Subfoveal & $2(20.0)$ & $4(40.0)$ & 0.6285 \\
\hline Juxtafoveal & $4(40.0)$ & $3(30.0)$ & 1.0000 \\
\hline Extrafoveal & $4(40.0)$ & $3(30.0)$ & 1.0000 \\
\hline \multicolumn{4}{|l|}{ Best-corrected visual acuity in study eye ${ }^{t}$} \\
\hline Number of letters (mean \pm SD) & $53.5 \pm 15.6$ & $56.1 \pm 11.7$ & 0.7653 \\
\hline \multicolumn{4}{|l|}{ Tonometry ${ }^{\dagger}$} \\
\hline Intraocular pressure, $\mathrm{mmHg}($ mean $\pm \mathrm{SD})$ & $15.4 \pm 2.7$ & $16.5 \pm 3.4$ & 0.6230 \\
\hline Previous treatment, $\mathrm{n}(\%)$ & $3(30.0)$ & $3(30.0)$ & 1.0000 \\
\hline $\mathrm{PDT}^{*}$ & $2(20.0)$ & $I(10.0)$ & 1.0000 \\
\hline Anecortave acetate ${ }^{*}$ & I $(I 0.0)$ & 0 & \\
\hline Bevacizumab $^{\S}$ & $3(30.0)$ & $2(20.0)-$ & \\
\hline Ranibizumab $^{\S}$ & 0 & I (10.0)- & \\
\hline
\end{tabular}

Notes: Group A: ranibizumab; group B: ranibizumab + PDT. *Chi-square test; $P<0.05$. 'Mann-Whitney $U$-test; $P<0.05$. ${ }^{\S}$ Previous treatment 6 months before inclusion. ¥Previous treatment 3 months before inclusion.

Abbreviations: CNV, choroidal neovascularization; PDT, photodynamic therapy; RAP, retinal angiomatous proliferation; SD, standard deviation.

mean age was 79.4 years (standard deviation $[\mathrm{SD}]=6.1$ ). At the time of inclusion, the most common RAP stage in both groups was stage II, which was present in six patients $(60 \%)$ in group A and five patients (50\%) in group B.

A total of six patients (three patients in group A and three patients in group B) had received some previous treatment for CNV in the study eye. Glaucoma was the most common previous ophthalmological condition in both groups in the nonstudy eye. Prior cataract surgery on the study eye was recorded in five patients $(50 \%)$ and two patients $(20 \%)$ in groups $A$ and $\mathrm{B}$, respectively. The most frequent signs were the presence of epithelial pigment alterations ( $70 \%$ and $40 \%$, respectively) and macular drusen (70\% and 60\%, respectively). Intraocular pressure was similar in both groups at baseline visit. The most common angiographic pattern in the study eye was minimally classic CNV in five patients of group A (50\%) and occult CNV in five patients of group B $(50 \%)$. OCT of the study eye at the time of inclusion showed five patients (50\%) in group A and three patients $(30 \%)$ in group $\mathrm{B}$ to have exudative retinal detachment, while eight patients (80\%) and six patients $(60 \%)$, respectively, presented cystoid macular edema.

No statistically significant differences were observed between the two groups for any of the characteristics analyzed - both being homogeneous in terms of the baseline clinical and biodemographic parameters.

Only two patients from group A were prematurely withdrawn from the study due to informed consent withdrawal by a patient and the onset of a severe concomitant disease which affected the participation of another patient in the clinical trial.

\section{Efficacy results}

The principal efficacy variable or endpoint of the study was the mean change in BCVA after 6 and 12 months, calculated with respect to baseline VA values for the patients in both treatment groups. The results obtained for groups $\mathrm{A}$ and $\mathrm{B}$ were: 1.30 (95\% confidence interval [CI]: -5.90 to 8.50$)$ and 7.60 (95\% CI: 1.20-14.00) after 6 months of follow-up, and 


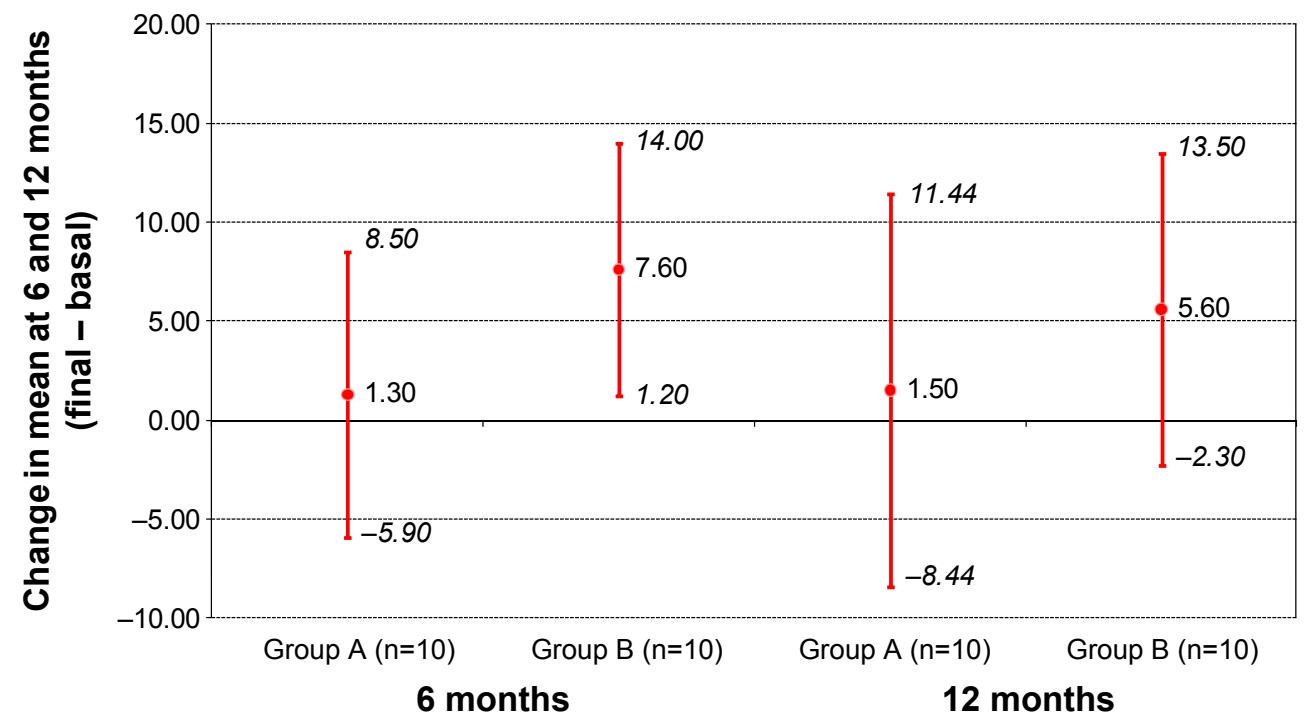

Figure I Changes in mean best-corrected visual acuity at 6 and 12 months.

Note: Values in italics are $P>0.05$ (as calculated by analysis of variance).

1.50 (95\% CI: -8.44 to 11.44$)$ and 5.60 (95\% CI: -2.30 to 13.50) after 12 months of follow-up, with no statistically significant differences observed according to treatment group (ANOVA; $P>0.05$ ) (Figure 1).

The percentage of patients showing improved BCVA, defined as a VA improvement of over five, ten, and 15 letters after 6 and 12 months of follow-up, versus baseline was determined. After 6 months of follow-up, $40 \%$ of the patients (four patients) in both groups presented a VA increase of over five letters, $10 \%$ (one patient) in group A and $20 \%$ (two patients) in group B showed an improvement of over ten letters, and 10\% (one patient) in group B showed a VA gain of over 15 letters. After 12 months of follow-up, $50 \%$ of the patients (five patients) in group A and 40\% (four patients) in group B showed a VA increase of over five letters, 30\% (three patients) in group A and 20\% (two patients) in group B showed a gain of over ten letters, and 20\% (two patients) in both groups showed an improvement of over 15 letters. No statistically significant differences were found between the two treatment groups or between the visits analyzed for each group (chi-square test; $P>0.05$ ) (Figure 2).

Regarding the evolution of VA, both groups showed statistically significant differences in the mean BCVA value versus baseline at visits 4 and 5 (months 4 and 5 of the trial) in group A, and at visits 4, 6, 7, and 11 (months 4, 6, 7, and 11 of the trial) in group B (Student's $t$-test; $P<0.05$ ).

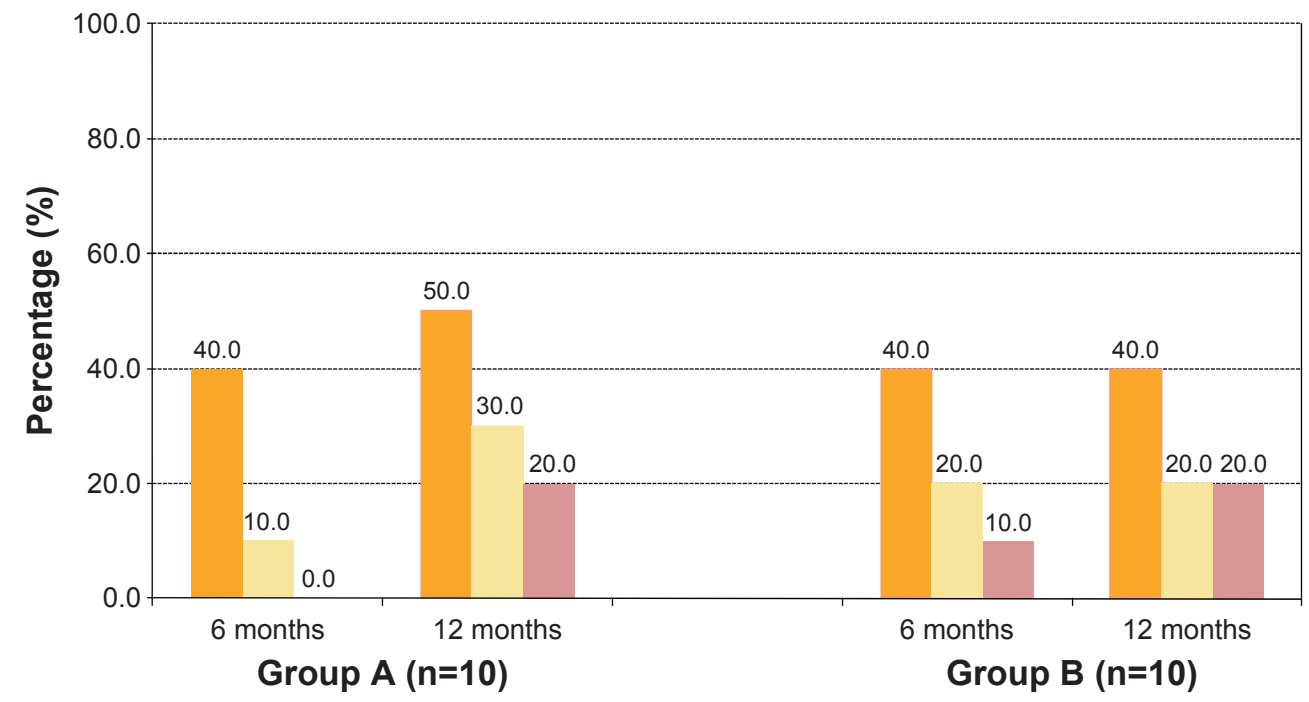

a $>$ letters $\square>10$ letters $\square>15$ letters

Figure 2 Visual acuity improvement at 6 and 12 months. 
Table 3 Evolution of morphological and functional characteristics

\begin{tabular}{|c|c|c|c|}
\hline & Group A $(n=10)$ & Group B $(n=10)$ & $P$-value \\
\hline \multicolumn{4}{|l|}{ Visual acuity, letters (mean \pm SD) } \\
\hline Baseline & $53.5 \pm 15.6$ & $56.1 \pm 11.7$ & 0.7653 \\
\hline 3 months & $57.7 \pm 20.1$ & $61.0 \pm 16.0$ & 1.0000 \\
\hline 6 months & $54.8 \pm 16.9$ & $63.7 \pm 13.2^{\circ}$ & 0.3374 \\
\hline 12 months & $55.0 \pm 17.6$ & $61.7 \pm 13.9$ & 0.2680 \\
\hline Mean changes, letters* (mean \pm SD) & $1.3 \pm 10.1$ & $7.6 \pm 8.9$ & 0.7089 \\
\hline \multicolumn{4}{|l|}{ Foveal thickness, $\mu \mathrm{m}$ (mean $\pm \mathrm{SD})$} \\
\hline Baseline & $438.7 \pm 86.6$ & $361.5 \pm 81.2$ & 0.0891 \\
\hline 3 months & $211.1 \pm 103.4^{\circ}$ & $181.3 \pm 39.1^{\circ}$ & 0.6878 \\
\hline 6 months & $246.4 \pm 90.2^{\circ}$ & $226.8 \pm 52.4^{\circ}$ & 1.0000 \\
\hline 12 months & $215.5 \pm 25.9^{\circ}$ & $215.1 \pm 34.4^{\circ}$ & 1.0000 \\
\hline Mean changes $(\mathrm{OCT}),{ }^{*} \mu \mathrm{m}($ mean $\pm \mathrm{SD})$ & $-236.3 \pm 109.6$ & $-146.4 \pm 91.0$ & 0.1499 \\
\hline \multicolumn{4}{|l|}{ Lesion size, $\mu \mathrm{m}($ mean $\pm \mathrm{SD})$} \\
\hline Baseline & $3,827.6 \pm 1,370.2$ & $3,297.7 \pm 1,740.7$ & 0.4965 \\
\hline 3 months & $1,719.3 \pm 2,067.3^{\circ}$ & $2,770.5 \pm 1,959.2^{\circ}$ & 0.2497 \\
\hline 6 months & $3,172.6 \pm 3,273.5$ & $3,065.1 \pm 2,273.5$ & 0.8340 \\
\hline 12 months & $3,268.6 \pm 3, \mid 49.1$ & $3,738.7 \pm 2,231.2$ & 0.6030 \\
\hline Mean changes (angiographic), ${ }^{*} \mu \mathrm{m}($ mean \pm SD) & $-622.9 \pm 3,003.3$ & $207.9 \pm 1,078.7$ & 0.4702 \\
\hline \multicolumn{4}{|l|}{ Total area of CNV, $\mathrm{mm}^{2}($ mean $\pm \mathrm{SD})$} \\
\hline Baseline & $1.9 \pm 1.6$ & $2.3 \pm 1.9$ & 1.0000 \\
\hline 3 months & $0^{\circ}$ & $0.7 \pm 1.3^{\circ}$ & 0.0939 \\
\hline 6 months & $1.0 \pm 1.4$ & $1.0 \pm 1.2$ & 0.9135 \\
\hline 12 months & $1.8 \pm 2.8$ & $1.2 \pm 1.8$ & 1.0000 \\
\hline Mean changes (angiographic), ${ }^{*} \mathbf{m m}^{2}($ mean $\pm \mathrm{SD})$ & -0.013 .6 & $-1.27 \pm 2.1$ & 0.4104 \\
\hline
\end{tabular}

Notes: Group A: ranibizumab; group B: ranibizumab + PDT. 'ANOVA test; $P<0.05$. ' $S$ tudent's $t$-test; $P<0.05$. *Mann-Whitney $U$-test; $P<0.05$.

Abbreviations: ANOVA, analysis of variance; CNV, choroidal neovascularization; OCT, optical coherence tomography; PDT, photodynamic therapy; SD, standard deviation.

The percentage of patients presenting a slight decrease in VA after 6 and 12 months of follow-up (defined as a loss of $<15$ letters vs baseline) was $10 \%$ (one patient) in both groups at 6 months, while a slight decrease was only present in $10 \%$ of the patients (one patient) in group B after 12 months. No significant differences were observed according to treatment group or between the visits analyzed for each group (chi-square test; $P>0.05$ ).

There were no statistically significant differences between the treatment groups regarding the presence of exudative retinal detachment determined by OCT during the study with respect to baseline (chi-square test; $P>0.05$ ).

Mean change in greatest linear dimension and in $\mathrm{CNV}$ size, measured by FA, and the mean change in foveal thickness as determined by OCT, after 3, 6, and 12 months versus baseline were analyzed. No statistically significant differences between treatment groups or visits were observed within the same group (ANOVA; $P>0.05$ ) (Table 3).

Regarding the number of retreatments in the two groups, no statistically significant intergroup differences were detected - the mean number per patient being $1.8(\mathrm{SD}=1.5)$ in group A and $0.9(\mathrm{SD}=1.4)$ in group B (Mann-Whitney
$U$-test; $P>0.05)$. The RAP relapse rate was $80.0 \%$ in group A and $40.0 \%$ in group $B$, and the mean time to retreatment was 3.1 months $(\mathrm{SD}=1.4)$ and 3.8 months $(\mathrm{SD}=0.0)$, respectively (Mann-Whitney $U$-test; $P>0.05$ ) (Table 4).

\section{Safety results}

Forty-five percent of the patients experienced some AE (six subjects in group A and three in group B), with no statistically significant differences found between the two groups (chi-square test; $P>0.05$ ).

\section{Table 4 Retreatment}

\begin{tabular}{llll}
\hline & $\begin{array}{l}\text { Group A } \\
(\mathbf{n}=1 \mathbf{0})\end{array}$ & $\begin{array}{l}\text { Group B } \\
(\mathbf{n}=1 \mathbf{0})\end{array}$ & P-value \\
\hline $\begin{array}{l}\text { Number of retreatments } \\
\text { (mean } \pm \text { SD)* }\end{array}$ & $1.8 \pm 1.5$ & $0.9 \pm 1.4$ & 0.1383 \\
$\begin{array}{l}\text { Time to retreatment, } \\
\text { months (mean } \pm \text { SD)* }\end{array}$ & $3.1 \pm 1.4$ & $3.8 \pm 0.0^{*}$ & 1.0000 \\
Relapse rate, n (\%) & $8(80.0)$ & $4(40.0)$ & 0.0679 \\
\hline
\end{tabular}

Notes: Group A: ranibizumab; group B: ranibizumab + PDT. *Mann-Whitney U-test; $P<0.05$. ${ }^{*}$ No data of visit 3 were available for one patient, so time to retreatment was calculated for three patients who received retreatment during visits 3-12. Abbreviations: PDT, photodynamic therapy; SD, standard deviation. 
None of the AEs reported during the trial were considered to be related to the study drug. Most of the AEs had mild intensity $(66.6 \%$ of those in group A and $100 \%$ of those in group B). The most frequent AEs were ear and labyrinth disorders (observed in two patients in group A and in one subject in group B) and ocular problems (seen in three cases in group B). In the course of the study, there was only one serious adverse event (SAE): the death of a patient in group A due to worsening of concomitant disease and not related to the study medication.

\section{Discussion}

RAP is considered to be a subtype of neovascular ARMD, ${ }^{1}$ differing from the latter in terms of the course of condition and response to treatment, ${ }^{7}$ with a poorer prognosis due to the absence of standardized treatment up to date. ${ }^{1,9,23}$ Therefore, any strategy offering stabilization or improvement constitutes an advancement in the management of the disease. In this sense, the contribution of this study with respect to previous studies on RAP is based upon its design. The present study is a prospective one with stratified randomization for both treatment regimens (ranibizumab in monotherapy or ranibizumab plus PDT with verteporfin) according to the stage of the disease, resulting in comparable, homogeneous groups.

In the present study, although no significant differences were observed between the groups regarding the analyzed efficacy variables, both treatment groups showed a tendency toward an increase in mean BCVA scores versus baseline values, after both 6 and 12 months of follow-up. This improvement in VA was greater in group B than in patients administered monotherapy (at 12 months: 5.60 letters vs 1.50 letters) (Figure 1). After 12 months, 20\% of the patients in both treatment groups showed a VA improvement of over three lines, and $30 \%$ and $20 \%$, respectively, showed more than two lines of gain in VA versus the baseline visit (Figure 2).

Starting in the fourth month of the study, a statistically significant increase in mean BCVA was noted versus baseline in both groups. At this point, ranibizumab loading phase had already ended, and thus, at least three intravitreous injections of the drug had been administered in both groups. Similar results were reported in a retrospective case review of 26 patients treated with ranibizumab $0.5 \mathrm{mg},{ }^{18}$ where $31 \%$ of patients showed a BCVA increment of over three lines after receiving the first three intravitreous injections of the loading phase.

In the present study and throughout the duration of follow-up, no statistically significant differences were observed between the treatment groups regarding the morphological changes in the retina as determined by FA or ICG (surface of the lesion or of the CNV) or in central foveal thickness as evidenced by OCT. However, on analyzing the mean change in foveal thickness, a decrease was observed in months 3, 6, and 12 versus baseline, thus suggesting a tendency toward improvement in both treatment groups, with comparatively greater improvement found in the ranibizumab monotherapy group.

Rouvas et $\mathrm{al}^{24}$ have published a randomized prospective trial with a 12-month follow-up, comparing the efficacy of three treatments: ranibizumab $0.5 \mathrm{mg}$ in monotherapy $(\mathrm{n}=13)$ or in combination with PDT with verteporfin $(n=13)$, and a combination of intravitreous triamcinolone with PDT with verteporfin ( $n=11)$; the criterion used for retreatment was the presence of sub- or intraretinal exudate.

In a similar way to our study, the above-mentioned study reported VA stabilization in all treatment groups at the end of follow-up, with no statistically significant differences between groups. In this context, combination of triamcinolone and PDT showed the best results, with no differences between the other two treatment groups. Likewise, the authors detected no differences in terms of the number of retreatments required by the patients administered ranibizumab in monotherapy (3.07) or in combination with PDT (0.46). ${ }^{24}$ In the present study, the mean number of retreatments in monotherapy group was almost one half after 12 months follow-up (1.8). This difference between monotherapy and combined therapy may be due to the time of retreatment administration according to protocol; intravitreal injection of ranibizumab could be administered every 30 days, while ranibizumab plus PDT should be administered every 90 days.

Regarding foveal thickness, Rouvas et $\mathrm{al}^{24}$ reported a decrease in all treatment groups, though significance was only reached in groups receiving combined therapy (ranibizumab with PDT and triamcinolone with PDT), which differed from our results wherein patients administered ranibizumab in monotherapy showed the most important anatomical changes.

Despite the differences between the two trials in terms of design, patient profile, method used for VA evaluation, and the treatment scheme employed, the results of the present study were similar to those published by Rouvas et al. ${ }^{24}$ The following should be noted: the latter study did not perform stratified randomization to therapy according to RAP stage; the VA measurements were based on a nonstandardized Snellen chart; all of the analyzed patients were naïve to 
treatment for CNV in the study eye; and the groups were not homogeneous in terms of RAP stage. In the present study, $30 \%$ of the patients in both groups had received some previous treatment for CNV in the study eye - a fact that may lead to a lower improvement observed during follow-up in terms of VA and foveal thickness. In this trend, Reche-Frutos et $\mathrm{al}^{27}$ had reported results from a prospective trial performed in non-naïve patients with RAP treated with ranibizumab in monotherapy at different stages. Their results suggested that a higher percentage of patients with previous treatment and a lower baseline VA could indicate a longer time of disease progression and greater structural involvement of the retina; so, a poorer response could be expected. In Reche-Frutos et al's study, all patients with no relapse of RAP after 12 months were in stage IIA of RAP, which indicates that monotherapy with ranibizumab could provide better response in patients with more superficial lesions. Confirming these findings, in the present study, only $20 \%$ of patients in the group treated with monotherapy showed no relapse in RAP lesion; this group showed majorly RAP stage II at baseline. Also, 30\% of patients had received previous treatment on the study eye.

More recently, Saito et $\mathrm{al}^{28}$ reported a retrospective case series review on patients with RAP who were naïve to treatment and majorly in RAP stage II and were treated with a combination of ranibizumab intravitreal injection and PDT with verteporfin; an increase of three lines or more in BCVA was reached in $50 \%$ of the treated eyes after 12 months of follow-up, in comparison with the results of the present study where only $20 \%$ of eyes treated with the combined treatment showed a similar increase in BCVA at 12 months.

Present data indicate that both studied treatments stabilized VA and foveal thickness after 6 and 12 months of follow-up, as shown by positive values obtained in the mean change in BCVA and negative values in the mean change in foveal thickness for both treatment groups. The results are in agreement with the results reported in a number of studies on ranibizumab in monotherapy ${ }^{18-20,27}$ or in combination with PDT. ${ }^{24,28,29}$ In this sense, the observed functional improvement (VA) proved greater for the combination of ranibizumab plus PDT with verteporfin, while from the anatomical perspective (foveal thickness), the greatest reduction corresponded to the group administered ranibizumab in monotherapy. This finding differs from the observations of other studies in which functional and anatomical improvement showed the same trend. ${ }^{18-20,24,28,30}$ Among other factors, this discrepancy may be due to the different profiles of the patients included in these studies, where subjects had not received previous treatment in the study eye and the initial RAP stage differed.

For a long time, PDT with verteporfin has been considered the gold standard treatment for RAP, ${ }^{7,9,12}$ despite the scanty encouraging results obtained. However, PDT in combination with other drugs (antiangiogenic agents or corticosteroids) $)^{14,15,17,22-24}$ might be a better approach for the treatment of advanced RAP lesions. Results obtained from recent studies seem to indicate that combined therapy consisting of intravitreal ranibizumab and PDT might require fewer treatments than an anti-VEGF agent in monotherapy. ${ }^{28,31}$ On the other hand, studies with bevacizumab ${ }^{22,23}$ in monotherapy or combined with verteporfin report results similar to those obtained in the present study, pointing to the combination treatment as a viable alternative in the management of RAP.

Regarding safety, no serious AEs related to the study drug were reported, and both groups showed a similar safety profile. These observations coincide with the available literature on ranibizumab $0.5 \mathrm{mg}$ used to treat this disorder. ${ }^{18-20,27,30}$

The main limitation of this study is that only 20 of the 30 initially planned subjects could be recruited due to the difficulty in identifying eligible patients. Nevertheless, the total number of subjects per group was similar to that of the only randomized trial published to date on ranibizumab and related to this condition. ${ }^{24}$ In addition, the stratified randomization according to RAP stage, the inclusion of patients previously treated for $\mathrm{CNV}$, and the use of standardized methods to assess efficacy and safety give validity to the present study results obtained with ranibizumab in monotherapy or combined with PDT with verteporfin in the treatment of RAP.

\section{Conclusion}

Results obtained in the present study warrant the need for randomized trials including a larger number of patients per treatment group, with a more representative profile of this disease, as seen by retinal specialists in clinical practice, and which may provide enough evidence for establishing an optimum treatment for RAP. Present study findings suggest that ranibizumab may be a valid therapeutic alternative in the management of RAP.

\section{Disclosure}

The authors report no conflicts of interest in this work.

\section{References}

1. Yanuzzi LA, Negräo S, Ida T, et al. Retinal angiomatous proliferation in age-related macular degeneration. Retina. 2001;21:416-423. 
2. Hunter MA, Dunbar MT, Rosenfeld PJ. Retinal angiomatous proliferation: clinical characteristics and treatment options. Optometry. 2004;75: 577-588.

3. Fernandez LH, Freund KB, Yannuzzi LA, et al. The nature of focal areas of hyperfluorescence or hot spots imaged with indocyanine green angiography. Retina. 2002;22:557-568.

4. Cohen SY, Creuzot-Garcher C, Darmon J, et al. Types of choroidal neovascularization in newly diagnosed exudative age-related macular degeneration. Br J Ophthalmol. 2007;91:1173-1176.

5. Maruko I, Iida T, Saito M, Nagayama D, Saito K. Clinical characteristics of exudative age-related macular degeneration in Japanese patients. Am J Ophthalmol. 2007;144:15-22.

6. Axer-Siegel R, Bourla D, Priel E, Yassur Y, Weinberger D. Angiographic and flow patterns of retinal choroidal anastomoses in agerelated macular degeneration with occult choroidal neovascularization. Ophthalmology. 2002;109:1726-1736.

7. Bottoni F, Massacesi A, Cigada M, Viola F, Musicco I, Staurenghi G. Treatment of retinal angiomatous proliferation in age-related macular degeneration: a series of 104 cases of retinal angiomatous proliferation Arch Ophthalmol. 2005;123:1644-1650.

8. Bressler NM. Retinal anastomosis to choroidal neovascularization: a bum rap for a difficult disease. Arch Ophthalmol. 2005;123: 1741-1743.

9. Gupta B, Jyothi S, Sivaprasad S. Current treatment options for retinal angiomatous proliferans (RAP). Br J Ophthalmol. 2010;94:672-677.

10. Slakter JS, Yannuzzi LA, Schneider U, et al. Retinal choroidal anastomoses and occult choroidal neovascularization in age-related macular degeneration. Ophthalmology. 2000;107:742-753.

11. Shimada H, Mori R, Arai K, Kawamura A, Yuzawa M. Surgical excision of neovascularization in retinal angiomatous proliferation. Graefes Arch Clin Exp Ophthalmol. 2005;243:519-524.

12. Boscia F, Furino C, Prascina F, Delle Noci N, Sborgia L, Sborgia C. Combined surgical ablation and intravitreal triamcinolone acetonide for retinal angiomatous proliferation. Eur J Ophthalmol. 2005;15: 513-516.

13. Kuroiwa S, Arai J, Gaun S, Iida T, Yoshimura N. Rapidly progressive scar formation after transpupillary thermotherapy in retinal angiomatous proliferation. Retina. 2003;23:417-420.

14. Boscia F, Furino C, Sborgia L, Reibaldi M, Sborgia C. Photodynamic therapy for retinal angiomatous proliferations and pigment epithelium detachment. Am J Ophthalmol. 2004;138:1077-1079.

15. Boscia F, Parodi MB, Furino C, Reibaldi M, Sborgia C. Photodynamic therapy with verteporfin for retinal angiomatous proliferation. Graefes Arch Clin Exp Ophthalmol. 2006;244:1224-1232.

16. Verteporfin in Photodynamic Therapy Study Group. Verteporfin therapy of subfoveal choroidal neovascularization in age-related macular degeneration: two-year results of a randomized clinical trial including lesions with occult with no classic choroidal neovascularization. Verteporfin in photodynamic therapy report 2. Am J Ophthalmol. 2001;131: 541-560.

17. Nicolo M, Ghiglione D, Lai S, Calabria G. Retinal angiomatous proliferation treated by intravitreal triamcinolone and photodynamic therapy with verteporfin. Graefes Arch Clin Exp Ophthalmol. 2006;244: 1336-1338.

Clinical Ophthalmology

\section{Publish your work in this journal}

Clinical Ophthalmology is an international, peer-reviewed journal covering all subspecialties within ophthalmology. Key topics include: Optometry; Visual science; Pharmacology and drug therapy in eye diseases; Basic Sciences; Primary and Secondary eye care; Patient Safety and Quality of Care Improvements. This journal is indexed on
18. Kramann C, Schöpfer K, Lorenz K, Zwiener I, Stoffelns BM, Pfeiffer N. Intravitreal ranibizumab treatment of retinal angiomatous proliferation. Acta Ophthalmol. 2012;90:487-491.

19. Konstantinidis L, Mameletzi E, Mantel I, Pournaras JA, Zografos L, Ambresin A. Intravitreal ranibizumab (Lucentis ${ }^{\circledR}$ ) in the treatment of retinal angiomatous proliferation (RAP). Graefes Arch Clin Exp Ophthalmol. 2009;247:1165-1171.

20. Atmani K, Voigt M, Le Tien V, et al. Ranibizumab for retinal angiomatous proliferation in age-related macular degeneration. Eye. 2010;24: 1193-1198.

21. Hermeida TS, Keane PA, Dustin L, Sadda SR, Fawzi AA. Long-term visual and anatomic outcomes following anti-VEGF monotherapy for retinal angiomatous proliferation. Br J Ophthalmol. 2010;94: 701-705.

22. Saito M, Shirigami C, Shiraga F, Nagayama D, Iida T. Combined intravitreal bevacizumab and photodynamic therapy for retinal angiomatous proliferation. Am J Ophthalmol. 2008;146:935-941.

23. Saito M, Shirigami C, Shiraga F, Kano M, Iida T. Comparison of intravitreal triamcinolone acetonide with photodynamic therapy and intravitreal bevacizumab with photodynamic therapy for retinal angiomatous proliferation. Am J Ophthalmol. 2010;149:472-481.

24. Rouvas AA, Papakostas TD, Vavvas D, et al. Intravitreal ranibizumab, intravitreal ranibizumab with PDT, and intravitreal triamcinolone with PDT for the treatment of retinal angiomatous proliferation: a prospective study. Retina. 2009;29:536-544.

25. Kim KJ, Li B, Houck K, Winer J, Ferrara N. The vascular endothelial growth factor proteins: identification of biologically relevant regions by neutralizing monoclonal antibodies. Growth Factors. 1992;7:53-64.

26. Mordenti J, Cuthbertson RA, Ferrara N, et al. Comparisons of the intraocular tissue distribution, pharmacokinetics, and safety of 125Ilabeled full-length and Fab antibodies in rhesus monkeys following intravitreal administration. Toxicol Pathol. 1999;27:536-544.

27. Reche-Frutos J, Calvo-Gonzalez C, Pérez-Trigo S, Fernandez-Perez C, Donate-Lopez J, Garcia-Feijoo J. Ranibizumab in retinal angiomatous proliferation (RAP): influence of RAP stage on visual outcome. Eur J Ophthalmol. 2011;21:783-788.

28. Saito M, Iida T, Kano M. Combined intravitreal ranibizumab and photodynamic therapy for retinal angiomatous proliferation. Am J Ophthalmol. 2012;153:504-514.

29. Nakano S, Homda S, Oh H, Kita M, Negi A. Effect of photodynamic therapy (PDT), posterior subtenon injection of triamcinolone acetonide with PDT, and intravitreal injection of ranibizumab with PDT for retinal angiomatous proliferation. Clin Ophthalmol. 2012;6:277-282.

30. Parodi MB, Iacono $P, M e n c h i n i ~ F$, et al. Intravitreal bevacizumab versus ranibizumab for the treatment of retinal angiomatous proliferation. Acta Ophthalmol. 2013;91:267-273.

31. Lee MY, Kim KS, Lee WK. Combination therapy of ranibizumab and photodynamic therapy for retinal angiomatous proliferation with serous pigment epithelial detachment in Korean patients: twelve-months results. Retina. 2011;31:65-73.

PubMed Central and CAS, and is the official journal of The Society of Clinical Ophthalmology (SCO). The manuscript management system is completely online and includes a very quick and fair peer-review system, which is all easy to use. Visit http://www.dovepress.com/ testimonials.php to read real quotes from published authors. 